\title{
ASSOCIATION FOR THE BEHAVIORAL SCIENCES AND MEDICAL EDUCATION
}

The fall meeting of ABSAME was held at the Allenberry Inn, Boiling Springs, Pennsylvania, from October 16 through October 19, 1977. The meeting considered medical student perspectives on behavioral science teaching, which included a panel of medical students; revision of the statement on educational goals; a panel of residents who talked about perceived needs and opportunities in the clinical years; and the usual format of workshops, media mart, and informal conversation.

A panel, "Training Physicians for Modern Practice," moderated by Shirley Nichols Fahey, was presented at the 88th Annual Meeting of the Association of American Medical Colleges.

Eugene B. Gallagher has become the ABSAME Newsletter editor. He can be reached in the Department of Behavioral Science, University of Kentucky Medical Center, Lexington, Kentucky 40506, while general correspondence should be directed to the address below.

The results of the election of officers of ABSAME are as follows: president-elect: Dewitt C. Baldwin, M.D.; members of the Board of Directors: Joseph G. Hollowell, M.D., and James McCorkel, Ph.D.

Mailing Address: Donald A. Kennedy, Ph.D., Secretary-Treasurer ABSAME, Department of Family and Community Medicine, Milton S. Hershey Medical Center, Hershey, Pennsylvania 17033.

CANADIAN PSYCHIATRIC ASSOCIATION

\section{COORDINATOR'S OF PSYCHIATRIC EDUCATION CANADA}

Official Action will appear in subsequent issues.

\section{SOCIETY OF PROFESSORS OF CHILD PSYCHIATRY}

The Society has not met since March 1977. Plans are still to hold the next annual meeting in the Southwest area of the country with the professors of child psychiatry of the OhioKentucky area to be in charge of the program. As always, the program is defined by the heads of divisions of child and adolescent psychiatry within that region. The chairman of this nonorganization is Henry Work, M.D., and the steering committee consists of Doctors Work, Irving Phillips, Jerry Weiner, Judith Forgetzen, Marshall Schechter, and James Sussex.

Mailing Address: Henry Work, M.D., American Psychiatric Association, 1700 18th Street, N.W., Washington, D.C. 20009. 